\title{
ARTICLE $\alpha$-Galactosylceramide and its analog OCH differentially affect the pathogenesis of ISO-induced cardiac injury in mice
}

\author{
Xin Chen ${ }^{1}$, Jie Liu ${ }^{1}$, Jie Liu ${ }^{1}$, Wen-jia Wang ${ }^{1}$, Wen-jing Lai ${ }^{2}$, Shu-hui Li ${ }^{3}$, Ya-fei Deng ${ }^{4}$, Jian-zhi Zhou ${ }^{5}$, Sheng-qian Yang ${ }^{1}$, Ying Liu ${ }^{6}$,
} Wei-nian Shou ${ }^{6}$, Da-yan Cao ${ }^{1}$ and Xiao-hui $\mathrm{Li}^{1}$

\begin{abstract}
Immunotherapies for cancers may cause severe and life-threatening cardiotoxicities. The underlying mechanisms are complex and largely elusive. Currently, there are several ongoing clinical trials based on the use of activated invariant natural killer T (iNKT) cells. The potential cardiotoxicity commonly associated with this particular immunotherapy has yet been carefully evaluated. The present study aims to determine the effect of activated iNKT cells on normal and $\beta$-adrenergic agonist (isoproterenol, ISO)-stimulated hearts. Mice were treated with iNKT stimulants, a-galactosylceramide (aGC) or its analog OCH, respectively, to determine their effect on ISO-induced cardiac injury. We showed that administration of aGC (activating both T helper type 1 (Th1)- and T helper type 2 (Th2)-liked iNKT cells) significantly accelerated the progressive cardiac injury, leading to enhanced cardiac hypertrophy and cardiac fibrosis with prominent increases in collagen deposition and TGF- $\beta 1$, IL-6, and alpha smooth muscle actin expression. In contrast to aGC, OCH (mainly activating Th2-liked iNKT cells) significantly attenuated the progression of cardiac injury and cardiac inflammation induced by repeated infusion of ISO. Flow cytometry analysis revealed that aGC promoted inflammatory macrophage infiltration in the heart, while $\mathrm{OCH}$ was able to restrain the infiltration. In vitro coculture of aGC- or OCH-pretreated primary peritoneal macrophages with primary cardiac fibroblasts confirmed the profibrotic effect of aGC and the antifibrotic effect of OCH. Our results demonstrate that activating both Th1- and Th2-liked iNKT cells is cardiotoxic, while activating Th2-liked iNKT cells is likely cardiac protective, which has implied key differences among subpopulations of iNKT cells in their response to cardiac pathological stimulation.
\end{abstract}

Keywords: a-galactosylceramide; OCH; iNKT cells; isoproterenol; cancer immunotherapy; cardiotoxicity; oncocardiology

Acta Pharmacologica Sinica (2020) 41:1416-1426; https://doi.org/10.1038/s41401-020-00517-z

\section{INTRODUCTION}

Depending on the type and progressive stage of cancer, treatment largely involves five therapeutic procedures, namely, surgical therapy, radiotherapy, conventional chemotherapy, targeted therapy, and immunotherapy [1]. Cardiotoxicity has been recognized as a major complication of cancer therapies other than surgical therapy and radiotherapy, as supported by the clinical observation that cancer survivors more commonly die from treatment-induced cardiotoxicity than from cancer recurrence $[1,2]$. For example, severe left ventricular dysfunction and heart failure have been found to be associated with cancer treatment with doxorubicin [3], ipilimumab [4], nivolumab [5], and other immunotherapies [6]. Thus, the cardiotoxicity of all cancer therapeutic drugs, including recent quickly developed novel immunotherapies, must be tested.

Invariant NKT cells (iNKT) cells, also known as type I NKT cells, are a major group of NKT cells in humans and mice [7]. By utilizing invariant T-cell receptor (TCR) alpha chains (Va24-Ja18 in humans and Va14-Ja18 in mice) with limited TCR beta chains to recognize lipid antigens presented by CD1d, iNKT cells can be readily identified [8]. Previously, it was demonstrated that iNKT cells are critical for the immune response to both viral infection and tumor development. Upon activation by lipid antigens or cytokines (IL-12/IL-18) [9], iNKT cells secrete large amounts of cytokines, such as IL-4, IL-10, and IFN- $\gamma$ (i.e., a mixture of $\mathrm{T}$ helper type 1 (Th1) and T helper type 2 (Th2) cytokines), to subsequently mediate their regulatory or proinflammatory functions [7]. Unlike peptide-MHC-restricted T cells, iNKT cells become mature upon leaving the thymus and acquire full effector function without priming $[7,8]$. These properties make iNKT cells important for the first line of defense and thus critical for establishing both innate and adaptive immunity. The quantity and/or function of iNKT cells are highly relevant to the overall survival rate of cancer patients $[10,11]$. It has been shown that the iNKT cell agonist a-galactosylceramide (aGC) potently induces tumor clearance in mouse models [11, 12]. Several clinical trials of strategies that enhance the antitumor immunity of iNKT cells via direct aGC administration or adoptive

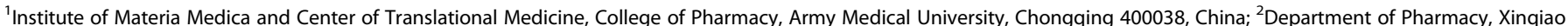

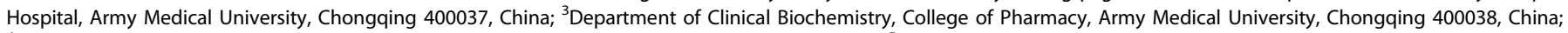

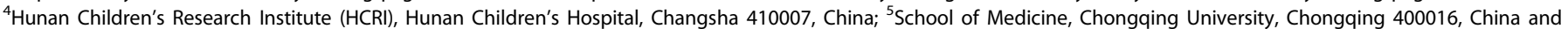
${ }^{6}$ Department of Pediatrics, Herman B Wells Center for Pediatric Research, Indiana University School of Medicine, Indianapolis, IN, USA

Correspondence: Da-yan Cao (dayancao@outlook.com) or Xiao-hui Li (Ips008@aliyun.com)

Received: 13 May 2020 Accepted: 19 August 2020

Published online: 24 September 2020 
transfer of iNKT cells (activated by aGC or modified by chimeric antigen receptor activation in vitro) are ongoing and have shown potentially promising results [13-19]. However, whether activated iNKT cell-based immunotherapies are cardiotoxic remains unknown. Our current study aimed to determine whether activated iNKT cells promote or enhance cardiac injury at baseline and under pathological stimulation by the $\beta$ adrenergic agonist isoproterenol (ISO). We found that aGC stimulation promoted ISO-induced cardiac injury, while its analog $\mathrm{OCH}$, another iNKT agonist, prevented ISO-induced cardiac injury. In vitro studies revealed that coculture with $\mathrm{OCH}$-treated primary macrophages induces reduced collagen secretion by fibroblasts, while aGC treatment promoted collagen synthesis. Our results suggest that aGC-based iNKT cell activation as an immunotherapy may have cardiotoxic effects in pathologically stimulated hearts, which implies that it may induce adverse effects in cancer patients with chronic cardiac injury.

\section{MATERIALS AND METHODS}

Animals

All animal procedures and protocols conformed to the US National Institutes of Health Guide for the Care and Use of Laboratory Animals (NIH Publication No. 85-23, revised 1996) and were approved by the ethics committee of Army Medical University. C57BL/6J mice were obtained from the Experimental Animal Center of Army Medical University and maintained at the animal center under specific pathogen-free conditions. All mice were given free access to standard laboratory mouse chow and tap water and housed on a 12-h light/dark cycle.

Mouse models of progressive and short-term cardiac injury Progressive cardiac injury: 8-10-week-old male C57BL/6 mice were subcutaneously infused with $5 \mathrm{mg} / \mathrm{kg}$ per day ISO for 1 week. Saline infusion was used as the control. aGC $(3 \mu \mathrm{g} /$ mouse) or $\mathrm{OCH}$ ( $3 \mu \mathrm{g} /$ mouse) was intraperitoneally injected every other day $2 \mathrm{~h}$ before ISO treatment. IL- 6 neutralizing antibody (50 $\mu \mathrm{g} / \mathrm{mouse}$ ) [20] or control IgG was intravenously injected via the tail vein once $2 \mathrm{~h}$ before establishment of the animal model of progressive cardiac injury. The mice were then sacrificed 7 days after ISO treatment.

Short-term cardiac injury: as previously reported [21], mice were subcutaneously injected with a single dose of ISO $(5 \mathrm{mg} / \mathrm{kg}$ of body weight) or saline ( $5 \mathrm{~mL} / \mathrm{kg}$ of body weight). aGC or OCH was intraperitoneally injected once $2 \mathrm{~h}$ before ISO treatment. The mice were then sacrificed at $72 \mathrm{~h}$ after ISO treatment.

No animals died prior to the end of the study.

\section{Western blotting}

Western blotting was performed as previously reported. Briefly, total protein was extracted and quantified, and equal amounts of protein were loaded on gels and subjected to SDS-PAGE. The proteins were then transferred to PVDF membranes (Bio-Rad) for blocking followed by primary and corresponding secondary antibody incubation and visualization with a chemiluminescence detection system. GAPDH (Cell Signaling Technology) was used as an internal control for protein loading. Only proteins from the left ventricle were subjected to Western blotting.

\section{Flow cytometry}

The cardiac immune cell detection protocol was adopted from previously reported protocols [22, 23]. Mice were euthanized with isoflurane, and the hearts were perfused with $20 \mathrm{~mL}$ of cold PBS. The harvested hearts were then finely minced and digested by shaking for $30 \mathrm{~min}$ at $37^{\circ} \mathrm{C}$. Then, the digested mixture was filtered through a 70- $\mu \mathrm{m}$ cell strainer and centrifuged for further staining.
Histology

Harvested hearts were fixed in $4 \%$ formaldehyde and embedded in paraffin. Then, each heart was sectioned and stained with hematoxylin-eosin or Masson trichrome (Sigma) according to the manufacturer's instructions. Microscopy images were analyzed with NIH ImageJ software.

\section{Cytokine determination}

Cardiac cytokine concentrations were determined by a commercialized multiplex immunoassay (Bio-Rad, stock number: M6000007NY), and the concentrations of the chemokines monocyte chemoattractant protein-1 (MCP-1) and macrophage inflammatory protein-1a (MIP-1a) were determined with a commercialized ELISA kit (Cloud-Clone). Heart tissues were mechanically homogenized in PBS and then subjected to two freeze-thaw cycles. The homogenates were centrifuged for 10 $\min$ at $10,000 \times g$, and the supernatants were immediately assayed following the manufacturer's instructions.

\section{Echocardiography}

Mice subjected to different treatments were anesthetized with $2.5 \%$ isoflurane on a temperature-controllable surgical table until a stable heart rate of $400-500$ beats per minute was reached. Then, the mice were subjected to echocardiography with a high resolution Micro-Ultrasound system (Vevo 2100) as previously reported [24]. Briefly, two-dimensional short-axis images were obtained with a mechanical scan probe. Short-axis images were further analyzed to derive M-mode images at the midpapillary level. Fractional shortening (FS) and ejection fraction (EF) were calculated by Vevo Analysis software according to the manufacturer's instructions.

Cardiac fibroblast isolation and cell (co)culture

Two-day-old C57BL/6 mice were subjected to a cardiac fibroblast isolation protocol. Briefly, the hearts were harvested, rinsed with PBS, and cut into fine pieces. Then, the hearts were digested (600 $\mathrm{U} / \mathrm{mL}$ collagenase II with $60 \mathrm{U} / \mathrm{mL}$ DNase I, Sigma), and erythrocytes were lysed (BD Bioscience) and filtered through a 70- $\mu \mathrm{m}$ cell strainer (BD Bioscience) to obtain a single-cell suspension of fibroblasts. Peritoneal macrophages were isolated as previously reported [25]. Peritoneal macrophages were isolated at $72 \mathrm{~h}$ after $\mathrm{a}-\mathrm{GC}$ or $\mathrm{OCH}$ treatment and then cocultured with fibroblasts in a Transwell system $\left(10^{6}\right.$ macrophages cocultured with $5 \times 10^{4}$ fibroblasts). Fibroblasts and macrophages were treated directly with a-GC $(100 \mathrm{ng} / \mathrm{mL})$ [26]. The coculture supernatants were then analyzed by collagens I and III (R\&D Systems), MCP-1, and MIP-1a (Cloud-Clone) ELISA kits according to the manufacturer's instructions.

Statistics

The results are presented as the mean \pm SD. Statistical analysis of differences between the means of two independent groups was performed by Student's $t$ test, whereas one-way ANOVA was used for multigroup comparisons (using LSD for intergroup comparisons). Statistical significance was defined as $P<0.05$ or $P<0.01$. Statistical analysis was performed with SPSS 22.0.

\section{RESULTS}

Activation of iNKT cells by aGC accelerates progressive ISO stimulation-induced cardiac fibrosis in mice

First, we tested whether activated iNKT cells have a detrimental effect on normal cardiac function and morphology. aGC $(3 \mu \mathrm{g} /$ mouse) was administered to 8-week-old mice once every other day for a month. Echocardiography is considered a first-line imaging method for cardiac function evaluation both clinically [27] and in mouse models. FS is the ratio of the diameters of the left ventricle at end diastole and end systole. EF is the percentage of 
a

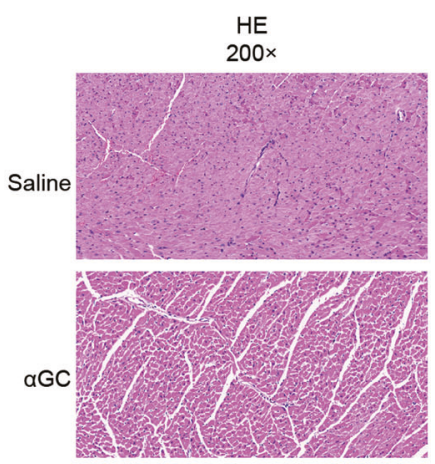

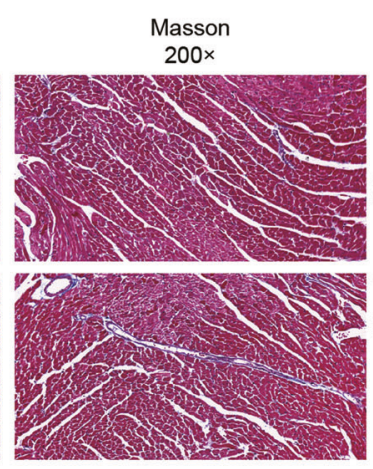

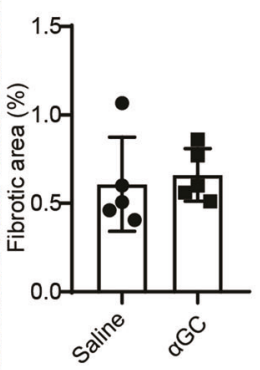

b
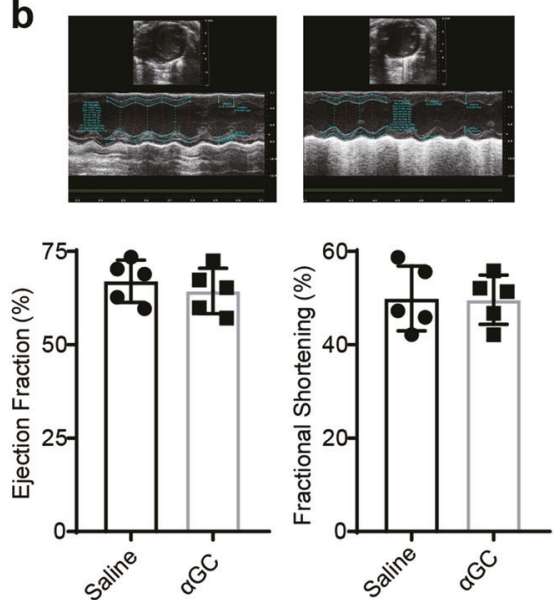

Fig. 1 Effects of long-term aGC treatment on cardiac morphology and function. $3 \mu \mathrm{g}$ of $\alpha \mathrm{GC}$ was administered to 8-week-old mice once every other day for 1 month. a HE staining and Masson's trichrome staining were performed to evaluate cardiac morphology. b Echocardiography was performed to evaluate cardiac function. The data are expressed as the mean \pm SD.

blood pumped out of the heart as it contracts. As demonstrated in Fig. 1 by morphological staining and echocardiography, we found no observable changes in the hearts of aGC-treated mice compared to those of wild type mice. To determine whether activated iNKT cells impact the heart under pathological stress, we used a pathological cardiac hypertrophy model. Under chronic stimulation of the $\beta$-adrenergic pathway with ISO, an irreversible pathological response that resulted in prominent cardiac hypertrophy and myocardial fibrosis was induced in the mouse heart. To determine whether aGC treatment enhances cardiac injury under this stress condition, experimental mice received ISO $(5 \mathrm{mg} /$ $\mathrm{kg}$ per day) stimulation for 7 days, and aGC ( $3 \mu \mathrm{g} / \mathrm{mouse})$ treatment was administered every other day for a total of three times. As expected, ISO stimulation resulted in cardiac hypertrophy and an increase in inflammatory cell infiltration compared to that induced by saline treatment (Fig. 2a-c). However, compared to those of ISO-treated mice, the hearts of ISO/aGCcotreated mice presented with a significant increase in the severity of collagen deposition despite similar heart weights (Fig. 2a-c). Western blotting was used to analyze myofibroblast activation using alpha smooth muscle actin ( $\alpha-S M A)$ and TGF- $\beta 1$ as molecular markers. We found slightly upregulated expression of $\alpha-S M A$ and significantly enhanced expression of TGF- $\beta 1$ in the ISO/aGC-cotreated group compared with the ISO alone-treated group (Fig. 2d-f). Cardiac function was evaluated by echocardiography. Our data indicated more severe impairment in cardiac function in hearts from ISO/aGC-cotreated mice than in those from mice treated with ISO alone (Fig. $2 g-i$ ).

As previously reported, ISO treatment is sufficient to induce the myocardial expression of several proinflammatory cytokines, which is important for promoting the progression of cardiac injury and cardiac remodeling [28]. As aGC stimulates NKT cells to produce both Th1- and Th2-like immune reactions, the levels of a panel of Th1 and Th2 cytokines (IL-1 $\beta$, IL-6, IL-10, IL-17A, TNF- $a$, and IFN- $\gamma$ ) were analyzed to further evaluate cardiotoxicity induced by aGC treatment. aGC treatment was found to promote the elevation of cardiac IL- 6 and IFN- $\gamma$ expression induced by chronic ISO stimulation, while the expression of TNF- $a, I L-1 \beta$, IL$17 \mathrm{~A}$, and IL-10 remained unchanged (Fig. 3). These results suggest that aGC treatment under $\beta$-adrenergic stimulation can result in enhanced inflammation and cardiotoxicity.

Activation of $\mathrm{TH} 2$-like iNKT cells by $\mathrm{OCH}$ attenuates progressive ISO stimulation-induced cardiac fibrosis in mice

Previously, it was shown that aGC stimulates iNKT cells to activate both Th1- and Th2-like immune responses, while $\mathrm{OCH}$, a sphingosine-truncated analog of aGC, mainly stimulates the Th2like immune response. Given the roles of the immune response in cardiac fibrosis at different stages, specifically the Th2-like immune response, which is thought to exert regulatory effects in early cardiac fibrosis [29,30], we tested the role of Th2-like NKT cell activation in the pathogenesis of cardiac fibrosis in response to chronic ISO treatment. As demonstrated in Fig. 4, compared to ISO treatment alone, $\mathrm{OCH}$ treatment significantly reduced heart hypertrophy and fibrosis in response to ISO stimulation (Fig. $4 a-c$ ). Consistently, TGF- $\beta 1$ and $\alpha-S M A$ expression was reduced to normal levels in $\mathrm{OCH}$-treated hearts, suggesting that the activation of myofibroblasts was inhibited by $\mathrm{OCH}$ (Fig. 4d-f). Echocardiography further indicated that $\mathrm{OCH}$ treatment partly rescued the impairment of cardiac function caused by ISO (Fig. $4 \mathrm{~g}-\mathrm{i}$ ). In addition, $\mathrm{OCH}$ treatment significantly suppressed the upregulation of IL-6 and TNF- $a$ expression induced by ISO treatment (Fig. 5). These results suggest that Th2-like NKT cell activation is able to reduce chronic ISO-induced cardiac injury.

aGC and $\mathrm{OCH}$ differentially regulate the pathogenesis of ISOinduced cardiac injury

In the clinic, rapid overactivation of sympathetic activity is strongly associated with the common fight-or-flight response. To test the effects of aGC and $\mathrm{OCH}$ on the cardiac response to acute $\beta$-adrenergic stimulation, we administered aGC or $\mathrm{OCH}$ to mice treated with a single dose of ISO $(5 \mathrm{mg} / \mathrm{kg})$ [21] and then evaluated heart injury based on the degree of cardiac collagen deposition. As shown in Fig. 6, consistent with the results produced by chronic ISO treatment, aGC significantly promoted ISO-induced cardiac collagen deposition, while OCH significantly blocked this elevation. In addition, aGC treatment did not promote ISO-induced cardiac weight gain, while $\mathrm{OCH}$ treatment restored the relative cardiac weight (Fig. 6c). Regarding cardiac cytokine concentrations, aGC treatment did not alter the cardiac IL- 6 concentration at $72 \mathrm{~h}$ after ISO treatment, while $\mathrm{OCH}$ partly reversed the ISO-induced cardiac IL-6 elevation (Fig. 6 d). The cardiac concentrations of IL-17A and IL-10 remained unchanged (Fig. S1), and IL-1 $\beta$ was not detectable by the assay. In addition, the cardiac concentrations of IFN- $\gamma$ and TNF- $\alpha$ were surprising, as the expression patterns of IFN- $\gamma$ and TNF-a generally did not appear to correspond with the observed morphological changes (Fig. 6e, f). IL-6, one of the most commonly changed cytokines in our current experimental setting, is a well-known proinflammatory cytokine that has been reported to be a potential therapeutic target in myocardial infarction (ClinicalTrials.gov Identifier: 
a

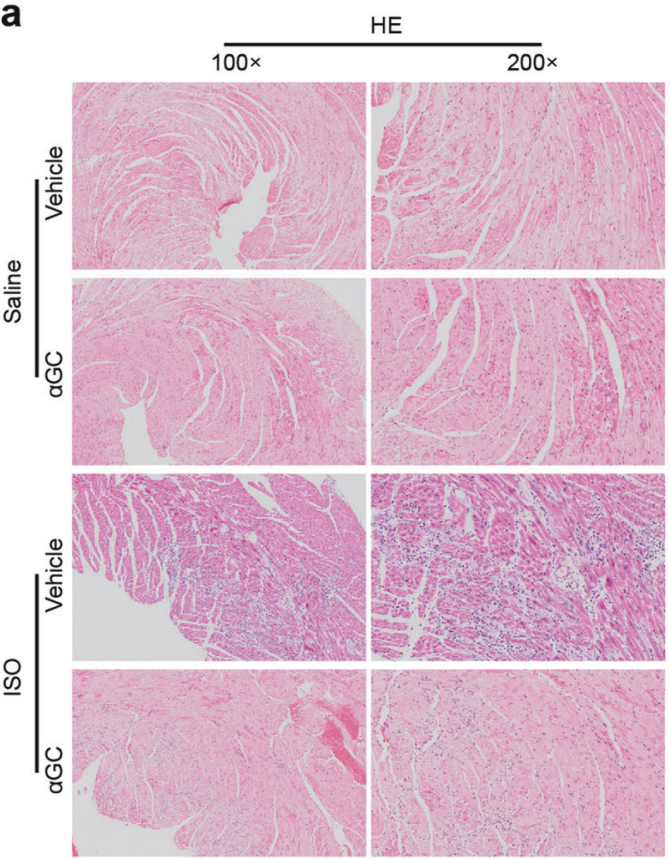

d

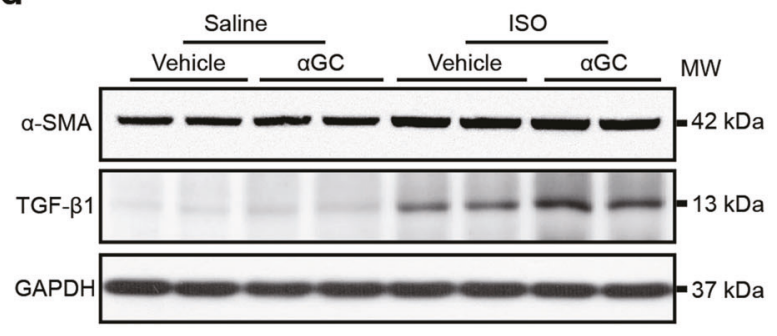

g
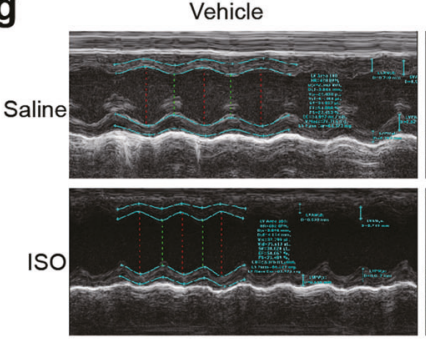

aGC
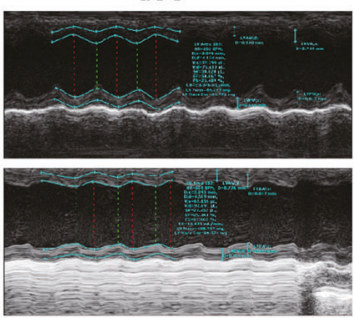

e

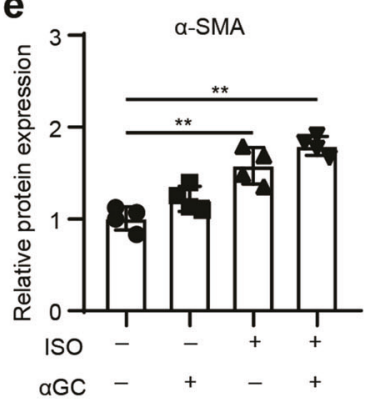

h

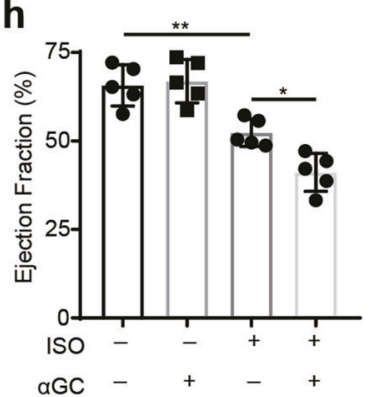

b
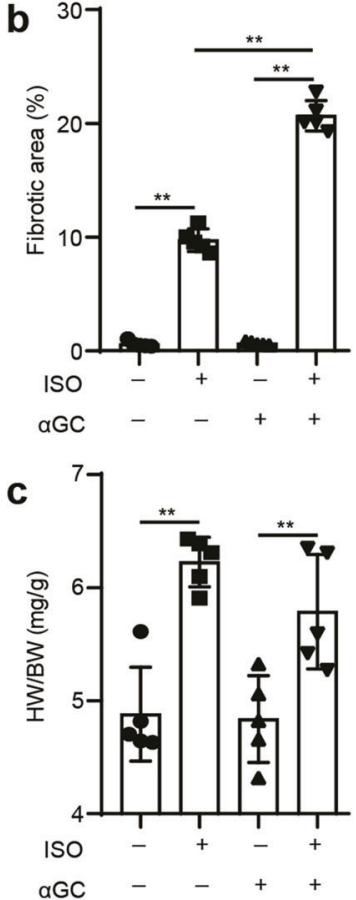

f

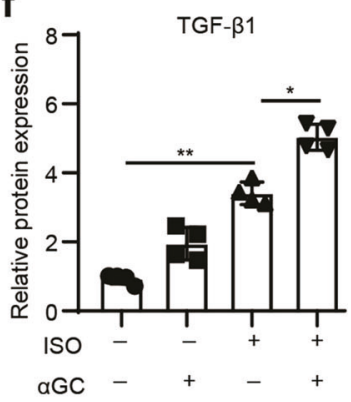

i

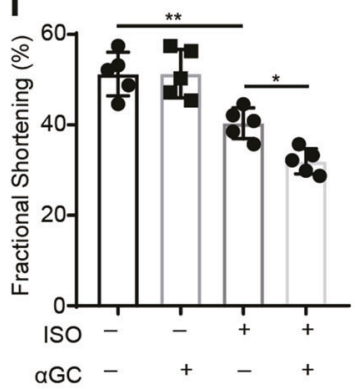

Fig. 2 iNKT cells activated by aGC accelerate progressive ISO stimulation-induced cardiac fibrosis in mice. WT C57BL/6 mice received ISO $(5 \mathrm{mg} / \mathrm{kg}$ per day) alone for 7 days or together with $\alpha \mathrm{GC}(3 \mu \mathrm{g} / \mathrm{mouse})$ every other day. a HE staining and Masson's trichrome staining were performed, and the fibrotic area/LV percentage (b) and ratio of heart weight to body weight (c) were calculated. $\mathbf{d}$, e, $\mathbf{f}$ Whole-heart lysates were subjected to immunoblotting with the indicated antibody. GAPDH was used as the loading control. The data are expressed as a ratio of the experimental value to the mean value of the saline group. $\mathbf{g}, \mathbf{h}, \mathbf{i}$ Echocardiography was performed to evaluate cardiac function. The data are expressed as the mean \pm SD. ${ }^{*} P<0.05$ and ${ }^{* *} P<0.01$.

NCT03004703) and in experimental myocarditis [31]. Thus, we administered an IL- 6 neutralizing antibody to animals subjected to aGC-induced cardiotoxicity. As shown in Fig. 7, morphological staining revealed that IL-6 neutralization only partly reversed aGC-induced cardiotoxicity, suggesting the complexity of this kind of cardiac injury. In addition, these results further support the notion that the Th1-like response promotes early progression in cardiac injury, while the Th2-like response inhibits this progression.
Cardiac macrophages in aGC-induced cardiotoxicity

The importance of cardioimmunology in health and disease is now widely recognized, and macrophages are the dominant cardiac leukocytes [32, 33]. Previous reports have revealed that cardiac-infiltrated macrophages promote pressure overloadinduced cardiac remodeling [34, 35]. Since aGC-induced cardiotoxicity significantly changes the cardiac inflammatory status, we hypothesized that aGC-induced cardiotoxicity may be closely related to the composition of macrophages. As shown 


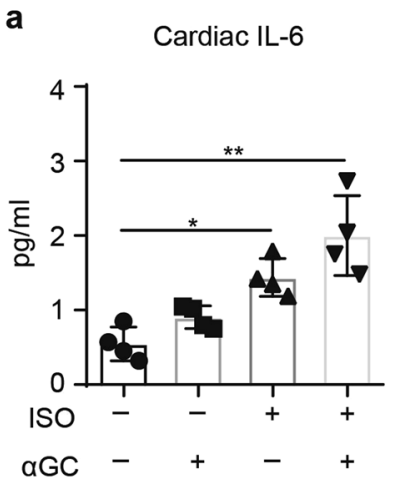

d

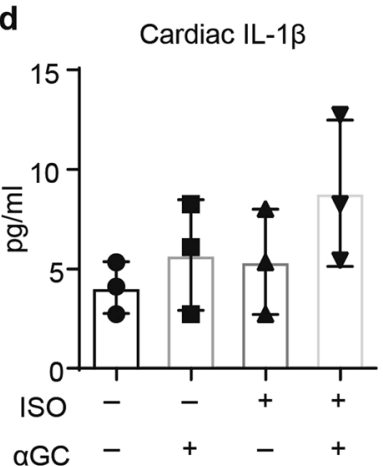

b

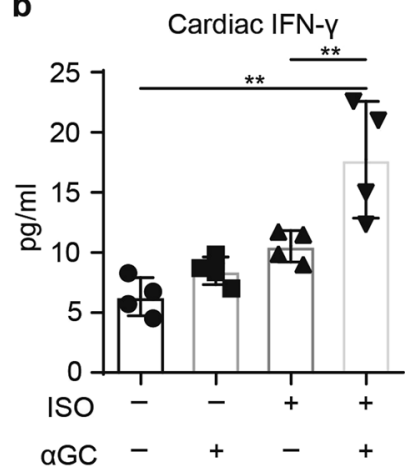

e

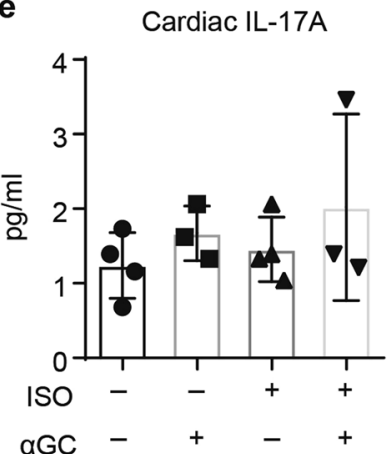

C

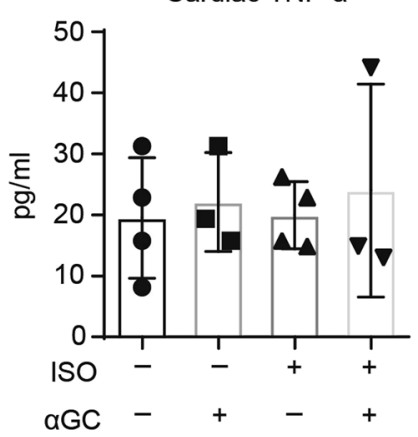

f

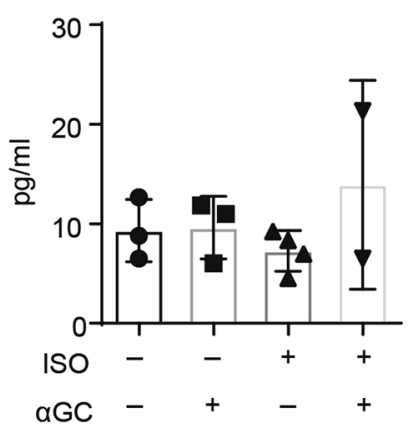

Fig. 3 Cytokine expression patterns after administration of ISO (5 mg/kg per day) alone for 7 days or with aGC ( $3 \mu \mathrm{g} / \mathrm{mouse}$ ) every other day. Whole-heart lysates were subjected to multiplex immunoassays to determine the protein concentrations of IL- 6 (a), IFN- $\gamma$ (b), TNF- $\alpha$ (c), IL-1 $\beta$ (d), IL-17A (e), and IL-10 (f). The data are expressed as the mean \pm SD. ${ }^{*} P<0.05$ and ${ }^{* *} P<0.01$.

previously, C-C chemokine receptor type 2 (CCR2) labels cardiacinfiltrated adult monocyte-derived macrophages [34, 36]. Flow cytometry showed that compared with saline treatment, ISO stimulation significantly increased the infiltration of $\mathrm{CCR}^{+}$ macrophages, and aGC treatment slightly aggravated this infiltration (Fig. 8a, b). In contrast, unlike saline, $\mathrm{OCH}$ treatment reversed chronic ISO stimulation-induced macrophage infiltration to a normal level (Fig. 8b). The levels of MCP-1 and MIP-1a, the two most important chemokines that mediate cardiac macrophage infiltration [37], were also determined by ELISA kits. Our results revealed the same tendency: aGC promoted the expression of MCP-1 and MIP-1a, while OCH inhibited ISOinduced promotion of chemokine expression (Fig. 8c, d). In addition, a single injection of aGC alone resulted in progressive cardiac macrophage infiltration, which peaked at $72 \mathrm{~h}$ after ISO treatment, in a time-dependent manner (Fig. S2a). Interestingly, a single injection of $\mathrm{OCH}$ decreased macrophage infiltration first and then promoted infiltration (Fig. S2b). Short-term aGC or $\mathrm{OCH}$ treatment did not affect the relative weight of cardiac tissues (Fig. S2c, d). It has been shown that the first several hours of cardiac macrophage infiltration are critical for the promotion of ISO-induced cardiac injury [21]. Thus, our findings may explain the contradiction between the activation of IFN- $\gamma$ and TNF- $a$ and cardiac morphological phenotypes. A single injection of aGC or $\mathrm{OCH}$ did not affect the relative weight of the heart.

To confirm the role of macrophages in aGC-induced cardiotoxicity in vitro, primary peritoneal macrophages were isolated, purified, stimulated with aGC or $\mathrm{OCH}$, and cocultured with mouse primary cardiac fibroblasts (Fig. 9b). Flow cytometry revealed that aGC pretreatment increased the proportion of $\mathrm{CCR}^{+}$macrophages, while $\mathrm{OCH}$ pretreatment did not change the proportion of $\mathrm{CCR}^{+}$macrophages (Fig. 9a). In this coculture system, we found that aGC pretreatment significantly promoted macrophage migration, while there was no significant macrophage migration following $\mathrm{OCH}$ pretreatment (Fig. 9c). In the supernatant of the cocultures, the concentrations of collagen I, collagen III, MCP-1, and MIP-1a were determined by ELISA. aGC treatment significantly promoted collagen III, MCP-1, and MIP-1a secretion, while $\mathrm{OCH}$ significantly decreased collagen III and MCP-1 secretion (Fig. 9d-f). The collagen I level was unchanged in the coculture supernatant regardless of pretreatment (Fig. 9d). Direct treatment of primary cardiac fibroblasts or primary peritoneal macrophages with aGC did not promote the secretion of collagen I, collagen III, MCP-1, or MIP-1a (Fig. S3). These results suggest that aGC-induced cardiotoxicity is closely related to the cardiac composition of macrophages.

\section{DISCUSSION}

Oncocardiology is a newly established research field aimed at minimizing cardiovascular risk and preventing cardiovascular disease in cancer treatment. Cardiotoxicity in cancer treatment was initially reported as early as the 1960s, when cardiovascular dysfunction associated with the use of daunomycin was documented [38]. Recently, a phase I clinical trial in which neuroblastoma was treated with GD2-CAR-NKT cells was performed [39]. The initial finding suggested that the treatment lead to cardiomegaly, a clear sign of cardiotoxicity (NCT03294954). Consistently, our present study revealed that therapies involving iNKT cell activation by aGC may promote cardiotoxicity in hearts exposed to pathological $\beta$-adrenergic signaling activation. The findings suggest the importance of cardiac pathological surveillance in iNKT cell-based cancer immunotherapy.

According to published epidemiological studies, more than half of patients with cancer therapeutic-related cardiac dysfunction die within 2 years of treatment [40, 41]. Although the underlying mechanisms associated with some chemotherapy-mediated 
a

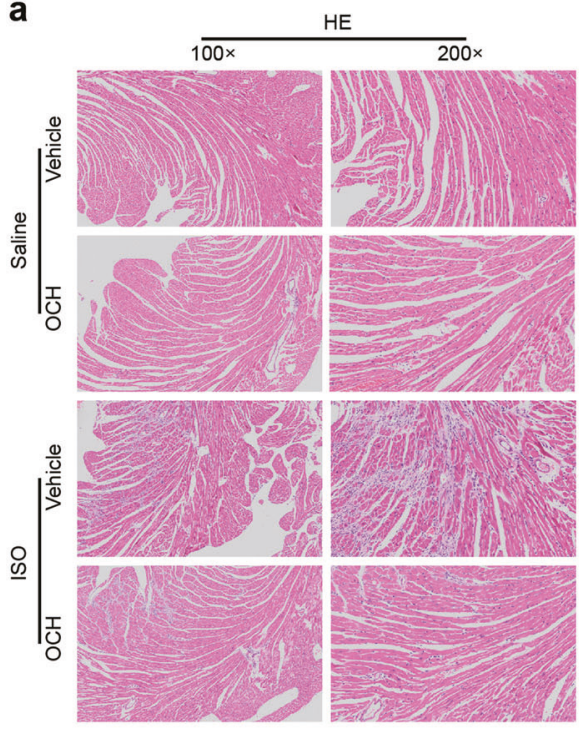

d

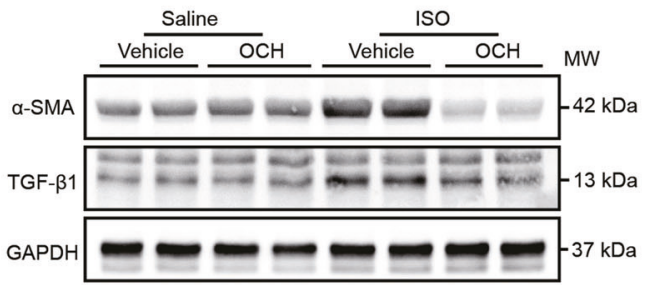

g

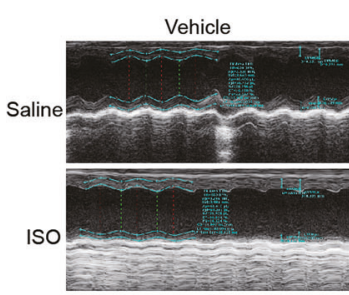

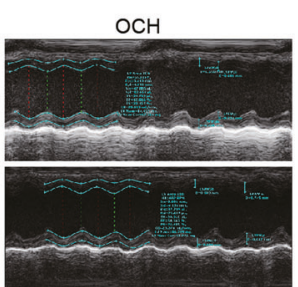

Masson
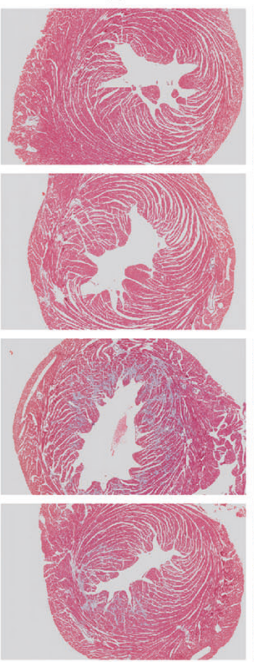

e

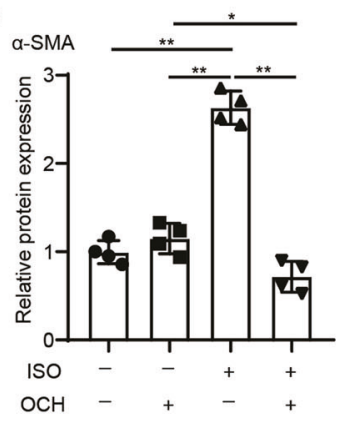

h

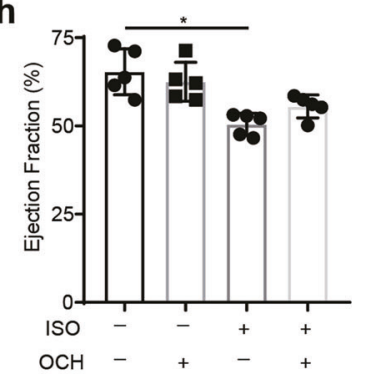

b

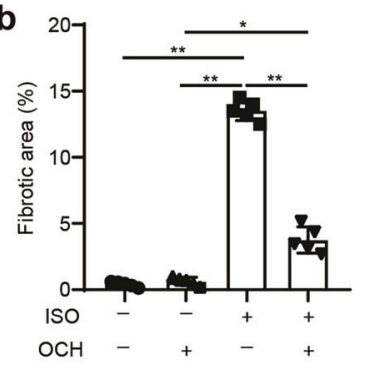

C

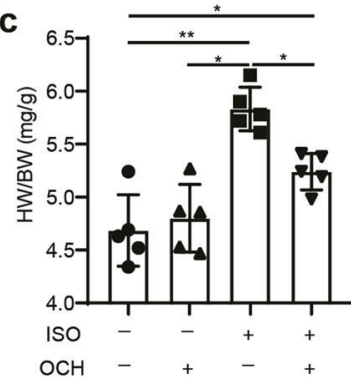

f

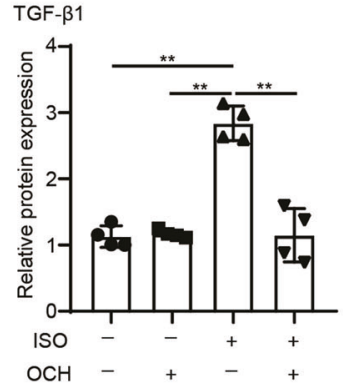

i

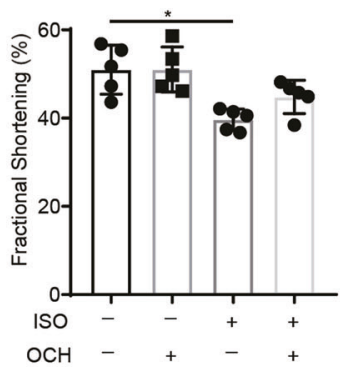

Fig. 4 iNKT cells activated by OCH attenuate progressive ISO stimulation-induced cardiac fibrosis in mice. WT C57BL/6 mice received ISO ( $5 \mathrm{mg} / \mathrm{kg}$ per day) alone for 7 days or with $\mathrm{OCH}$ ( $3 \mu \mathrm{g} / \mathrm{mouse}$ ) every other day. a HE staining and Masson's trichrome staining were performed, and the fibrotic area/LV percentage (b) and ratio of heart weight to body weight (c) were calculated. $\mathbf{d}$, e, $\mathbf{f}$ Whole-heart lysates were subjected to immunoblotting with the indicated antibody. GAPDH was used as the loading control. The data are expressed as a ratio of the experimental value to the mean value of the saline group. $\mathbf{g}, \mathbf{h}, \mathbf{i}$ Echocardiography was performed to evaluate cardiac function. The data are expressed as the mean \pm SD. ${ }^{*} P<0.05$ and ${ }^{* *} P<0.01$.

cardiotoxicities have been well studied, the full spectrum of immunotherapy-induced cardiac injuries is poorly defined. To our knowledge, the present study revealed for the first time that iNKT cell activation-based tumor immunotherapy could be potentially harmful to the heart if care is not taken. As it was demonstrated that aGC-promoted cardiotoxicity can be partly inhibited by an IL6 neutralizing antibody, it is highly likely that the cardiotoxicity of iNKT cell activation is largely due to the promotion of prior cardiac injury mediated by pathogenic cytokines. This finding is consistent with the clinical observation that potentially life-threatening cytokine release syndrome (CRS) is the main adverse effect of chimeric antigen receptor T-cell therapy. CRS [42, 43], which is characterized by signs of supraphysiological levels of inflammatory cytokines, is the most common toxic effect of CAR-T therapy and has a remarkably high incidence rate (70\%-90\%) [44]. In addition, in accordance with previously published literature [31], we also found that blocking cytokine release was potentially cardio-protective. However, our work also revealed that, unlike CAR-T therapy, NKT cell activation might profoundly affect innate immune cell infiltration of cardiac tissues, which could be another critical driver of cardiac injury. A previous report by Xiao et al. demonstrated that cardiac innate immune cell dysfunction is secondary to ISO stimulation-induced IL-18 release [21]. Therefore, the relationship between CRS and cardiac immune cell infiltration in the setting of immunotherapy needs to be further determined. Interestingly, our study also suggested that the activation of Th2-like iNKT cells is beneficial to the heart. Taking advantage of different cell-surface markers and signature transcription factors, 


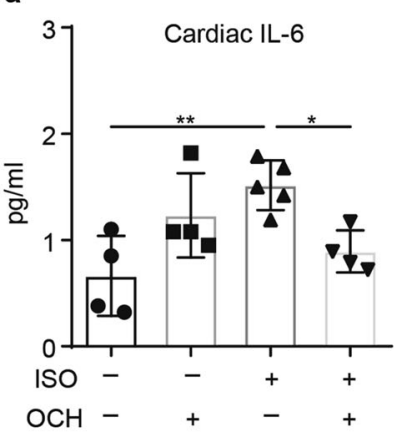

d

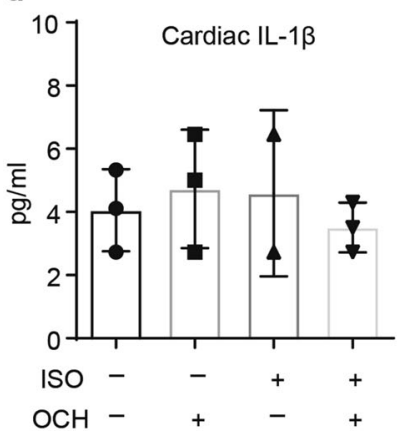

b

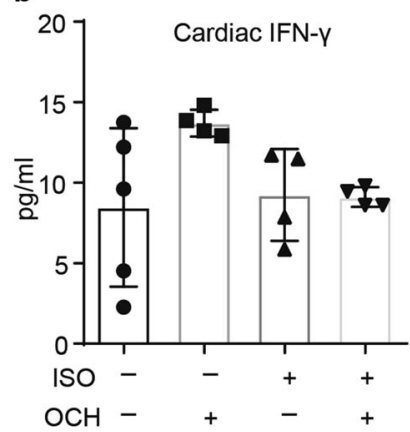

e

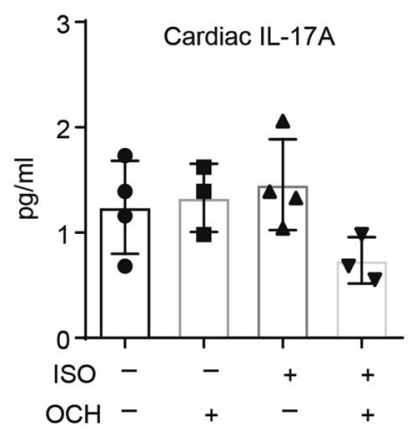

c

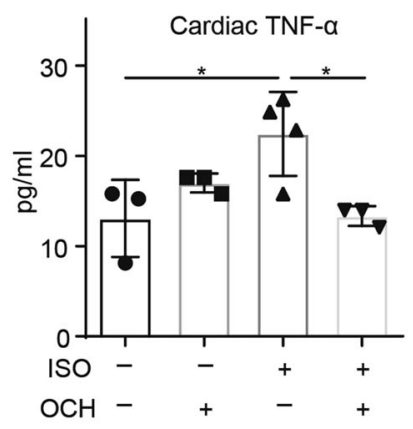

f

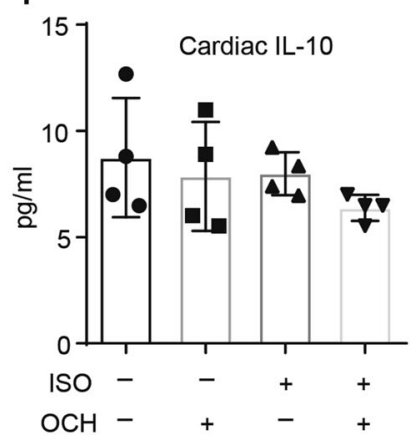

Fig. 5 Cytokine expression patterns after administration of ISO ( $5 \mathrm{mg} / \mathrm{kg}$ per day) alone for 7 days or with $\mathrm{OCH}$ ( $3 \mu \mathrm{gg} / \mathrm{mouse}) \mathrm{every}$ other day. Whole-heart lysates were subjected to multiplex immunoassays to determine the protein concentrations of IL-6 (a), IFN- $\gamma$ (b), TNF- $\alpha$ (c), IL$1 \beta$ (d), IL-17A (e), and IL-10 (f). The data are expressed as the mean \pm SD. ${ }^{*} P<0.05$ and ${ }^{*} P<0.01$.

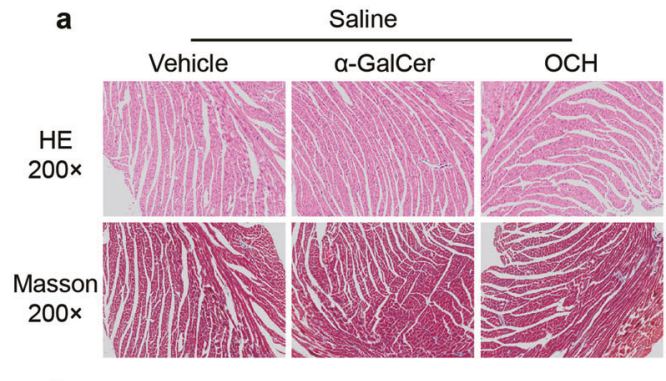

b

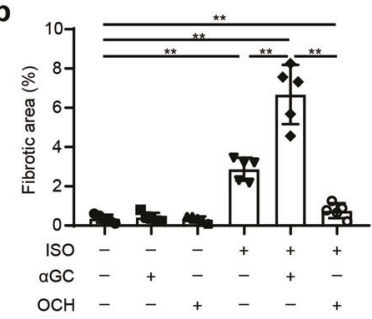

e

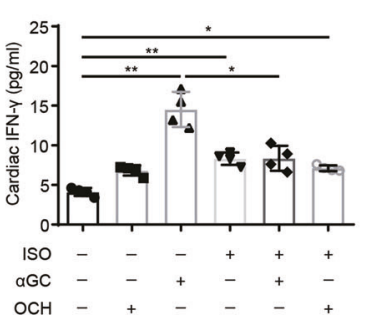

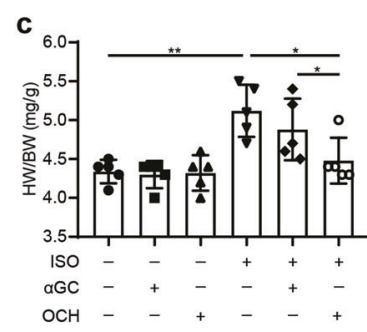

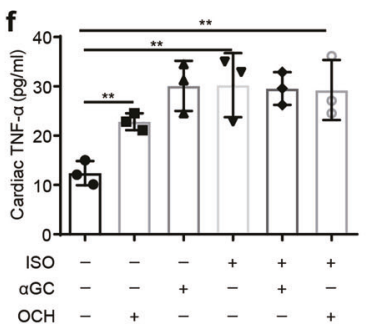

Fig. 6 aGC and OCH differentially regulate the pathogenesis of cardiac injury induced by a single dose of ISO. WT C57BL/6 mice were pretreated with $\alpha \mathrm{GC}$ or $\mathrm{OCH}$ and then received ISO $(5 \mathrm{mg} / \mathrm{kg}$ per day) only once. a HE staining and Masson's trichrome staining were performed, and the fibrotic area/LV percentage (b) and ratio of heart weight to body weight (c) were calculated. Whole-heart lysates were subjected to multiplex immunoassays to determine the protein concentrations of IL- 6 (d), IFN- $\gamma(\mathbf{e})$, and TNF- $\alpha$ (f). The data are expressed as the mean \pm SD. ${ }^{*} P<0.05$ and ${ }^{* *} P<0.01$. 
a

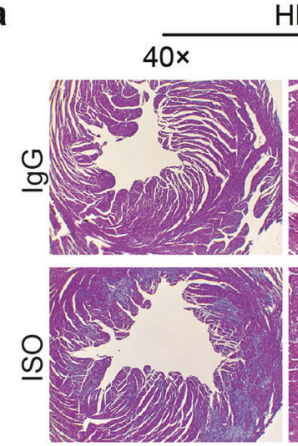

$\mathrm{HE}$
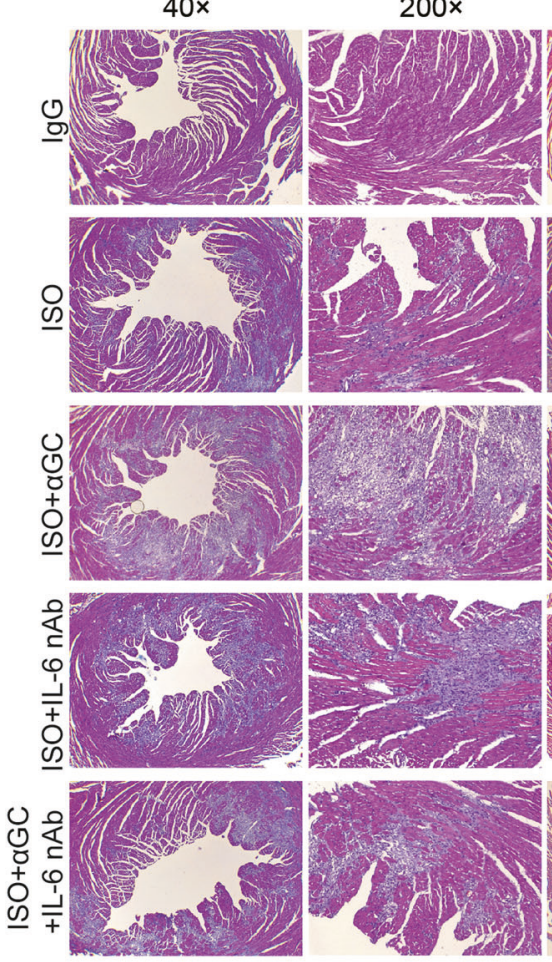

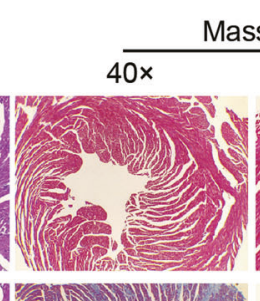

Masson

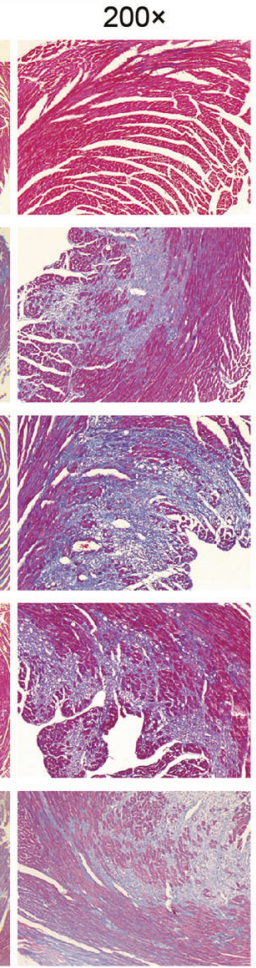

b

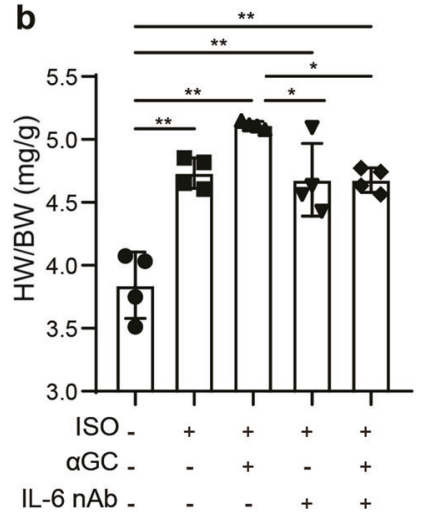

c

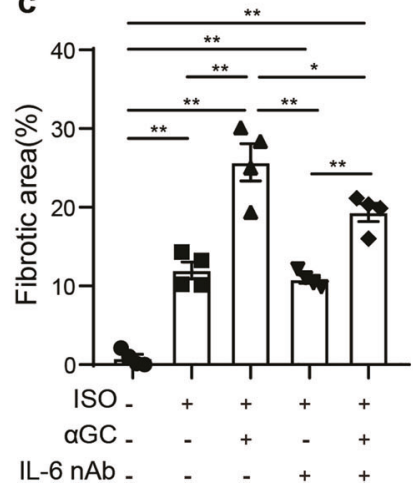

Fig. 7 aGC-induced acceleration of progressive ISO stimulation-induced cardiac fibrosis was partly reversed by an IL-6 neutralizing antibody. WT C57BL/6 mice received ISO $(5 \mathrm{mg} / \mathrm{kg}$ per day) alone for 7 days or together with $\alpha \mathrm{GC}(3 \mu \mathrm{g} / \mathrm{mouse})$ every other day following IL- 6 neutralizing antibody ( $50 \mu \mathrm{g} /$ mouse) pretreatment. a HE staining and Masson's trichrome staining were performed, and the ratio of heart weight to body weight $(\mathbf{b})$ and fibrotic area/LV percentage $(\mathbf{c})$ were calculated. The data are expressed as the mean \pm SD. ${ }^{*} P<0.05$ and ${ }^{* *} P<0.01$

functional iNKT cell subsets can be distinguished. Generally, two major iNKT subsets have been identified: one is proinflammatory iNKT cells (NKT1 and NKT17 cells), which are analogous to Th1 and Th17 cells and mainly secrete IL-2, IL-17, IL-22, TNFa, and IFNy; the other is regulatory iNKT cells (NKT2, NKT10, and $\mathrm{NKT}_{\mathrm{FH}}$ cells), which are analogous to Th2, Th10, and regulatory $T$ cells $\left(T_{\text {Reg }}\right)$ and mainly secrete IL-4, IL-10, IL-13, and IL-21 [7]. This functional heterogeneity of iNKT cells explains why NKT cells play opposite roles in different immune-related diseases. For example, iNKT cell activation helps fight hepatitis $C$ virus infection through rapid expansion and IFNy production [45], while hepatic iNKT cell accumulation and IL-13 production promote nonalcoholic steatohepatitis and hepatic fibrosis [46].

In a mouse model of myocardial ischemia/reperfusioninduced cardiac injury, reports have revealed that aGC treatment ameliorates postinfarct cardiac remodeling [46, 47]. In addition, aGC administration has also been reported to attenuate angiotensin II-induced cardiac remodeling in mice. Both of the independent groups behind these studies noted that the protective role of iNKT cell activation in cardiac remodeling may occur via IL-10 signaling [48]. Our current study revealed that aGC administration promoted ISO-induced cardiac injury. Although the mechanism of ISO-induced cardiac fibrosis is complex, the initiation of cardiac injury induced by ISO is closely related to myocyte necrosis [49]. Necrotic myocytes then initiate cardiac inflammation (mainly Th1-like reactions) and collagen synthesis and deposition. Based on such observations, targeting early stage inflammation is thought to be beneficial for preventing the progression of cardiac fibrosis $[29,30,50]$. As the previously developed iNKT cell agonist aGC stimulates the release of a mixture of proinflammatory and regulatory cytokines while $\mathrm{OCH}$ stimulation results in the release of primarily regulatory cytokines, we believe that regulatory cytokines may limit ISO-induced cardiac injury. In addition, as regulatory cytokines inhibit antitumor immunity, we anticipate that it would be difficult to treat cardiac injury with these cytokines.

Some limitations of the present study are worth mentioning. First, the number and functional subsets of iNKT cells are different between humans and mice $[7,8]$. In mice, iNKT cells can account for up to $20 \%-50 \%$ and $10 \%-25 \%$ of the T cells in the liver and adipose tissue, respectively. Significantly less proportions $(<2 \%)$ of iNKT cells can also be found in the murine thymus, spleen, and blood. Only adipose tissue exhibits a comparable frequency of iNKT cells in humans, while in other human organs (the liver and blood), there are much fewer iNKT cells than in mouse organs. Limited by sample accessibility, the subsets of iNKT cells in humans are less well documented as well. Second, aGC administration was not performed in a tumorbearing context in the present study, and the cardiotoxicity of proinflammatory NKT activation remains to be further confirmed. Third, in situ cardiac iNKT cell identification was not performed because of technical limitations. We and another group found that current techniques for iNKT cell identification are poor [51]. Further studies utilizing genetically modified mice for in situ iNKT cell observation during the pathogenesis of cardiac remodeling are needed.

Our study indicates that the activation of iNKT cells by aGC promotes and $\mathrm{OCH}$ alleviates, cardiac injury induced by $\beta$ adrenergic stimulation, suggesting that there are key differences 
a

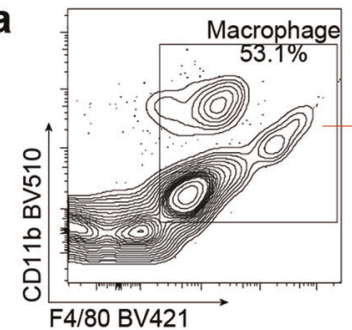

b Cardiac Inflitrated Macrophage

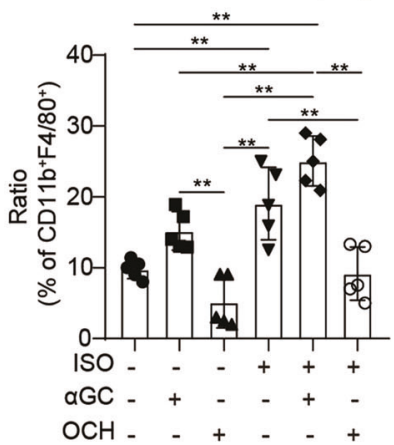

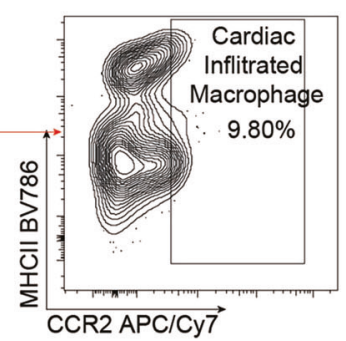

C

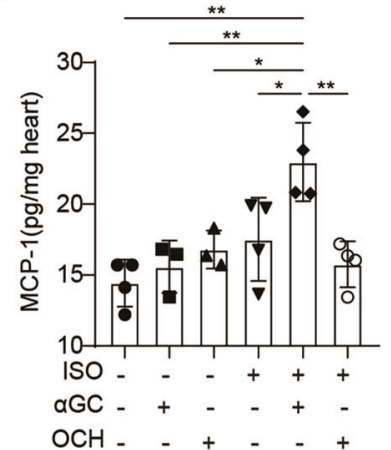

d

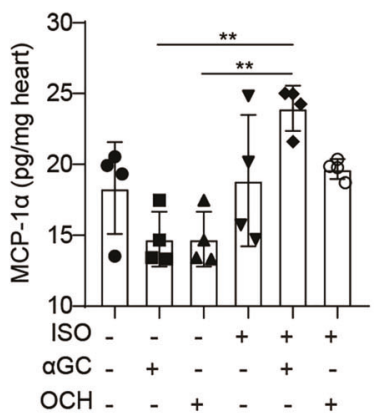

Fig. 8 Cardiac macrophages in aGC-induced cardiotoxicity. a-c Hearts were harvested from mice stimulated with ISO (5 mg/kg per day) alone for 7 days or together with $\alpha \mathrm{GC}$ or OCH every other day. a FACS was used to analyze the proportions of macrophages and adult monocytederived macrophages (infiltrated) in the hearts. b The percentage of CCR2-positive macrophages among CD11 b $\mathrm{b}^{+} / 80^{+}$cells was calculated. c, $\mathbf{d}$ Whole-heart lysates were subjected to ELISA immunoassays to determine the protein concentrations of MCP-1 and MIP-1 $\alpha$. The data are expressed as the mean $\pm S D$. ${ }^{*} P<0.05$ and ${ }^{* *} P<0.01$.

a

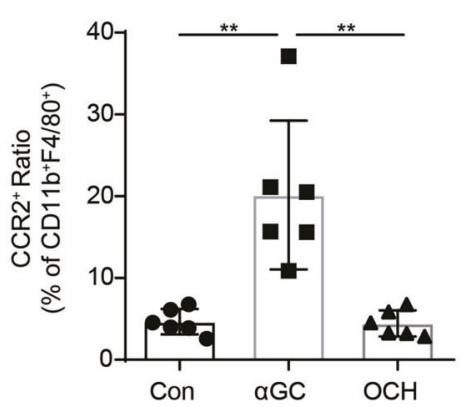

d

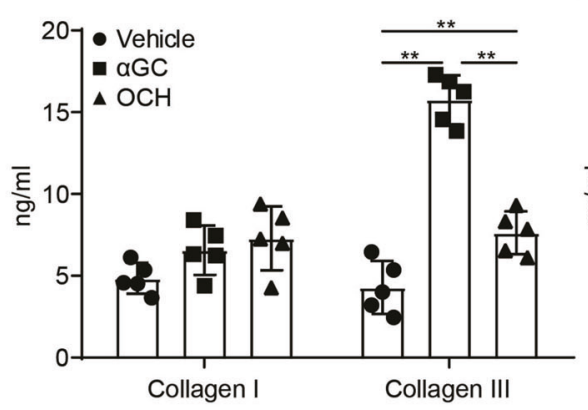

b

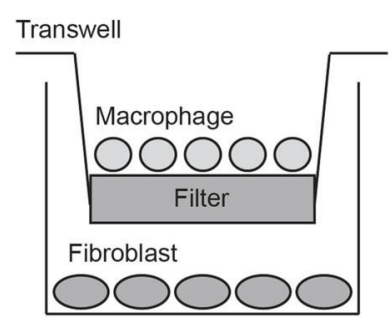

e

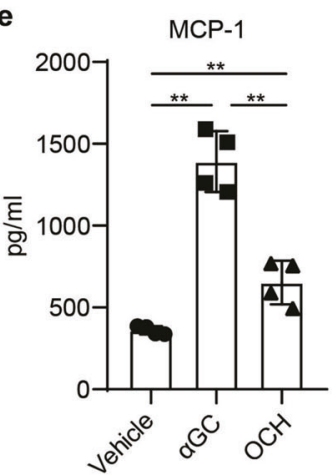

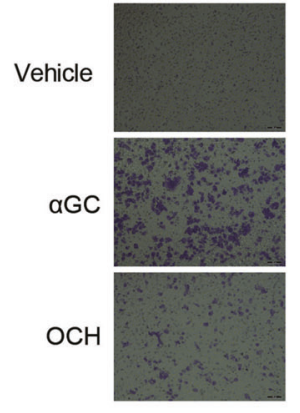

f

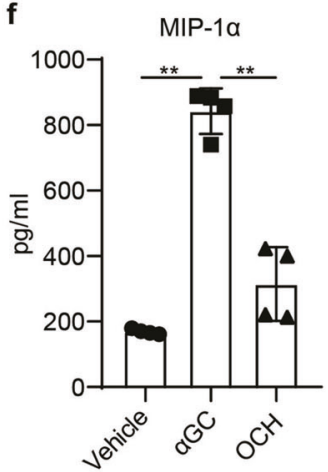

Fig. 9 The effect of iNKT cell activation on naive fibroblast cells. $\alpha$ GC- or OCH-stimulated primary peritoneal macrophages were isolated, purified, and cocultured with mouse primary cardiac fibroblasts. a The percentage of CCR2-positive macrophages among $C D 11 \mathrm{~b}^{+} \mathrm{F} 4 / 80^{+}$cells was calculated. b Schematic diagram of the coculture system. $\mathbf{c}$ Representative image of migrated cells. The protein concentrations of collagen I (d), collagen III (d), MCP-1 (e), and MIP-1 $\alpha$ (f) in the supernatants of cardiac fibroblasts were determined at the indicated time points with a commercialized ELISA kit. The data in graphs represent the mean \pm SD. ${ }^{* *} P<0.01$. 
among subpopulations of iNKT cells in their response to cardiac pathophysiological stimulation. Thus, it is important to evaluate the potential cardiotoxicity of various potential cancer treatments based on the strategy of iNKT cell activation.

\section{ACKNOWLEDGEMENTS}

This study was funded by the National Natural Science Foundation of China (\#81773742 and \#81520108029 to XHL, \#81703521 to YFD, and \#81473260 to JZZ).

\section{AUTHOR CONTRIBUTIONS}

$\mathrm{XHL}$, and DYC, designed research; XC, JL, JL, WJW, YFD, SQY, and WJL, performed research; $\mathrm{XC}, \mathrm{SHL}, \mathrm{YL}$, and DYC, analyzed data; $\mathrm{XC}$, and DYC, drafted the paper; DYC WNS, JZZ, and $X \mathrm{HL}$, revised and finalized the paper. All authors contributed to and have approved the paper.

\section{ADDITIONAL INFORMATION}

The online version of this article (https://doi.org/10.1038/s41401-020-00517-z) contains supplementary material, which is available to authorized users.

Competing interests: The authors declare no competing interests.

\section{REFERENCES}

1. Zheng PP, Li J, Kros JM. Breakthroughs in modern cancer therapy and elusive cardiotoxicity: critical research-practice gaps, challenges, and insights. Med Res Rev. 2018;38:325-76.

2. Totzeck M, Schuler M, Stuschke M, Heusch G, Rassaf T. Cardio-oncology-strategies for management of cancer-therapy related cardiovascular disease. Int $J$ Cardiol. 2019:280:163-75.

3. Doroshow JH. Doxorubicin-induced cardiac toxicity. $N$ Engl J Med. 1991;324:843-5.

4. Roth ME, Muluneh B, Jensen BC, Madamanchi C, Lee CB. Left ventricular dysfunction after treatment with ipilimumab for metastatic melanoma. Am J Ther. 2016;23:e1925-8.

5. Matson DR, Accola MA, Rehrauer WM, Corliss RF. Fatal myocarditis following treatment with the PD-1 inhibitor nivolumab. J Forensic Sci. 2018;63:954-7.

6. Quagliariello V, Passariello M, Coppola C, Rea D, Barbieri A, Scherillo M, et al. Cardiotoxicity and pro-inflammatory effects of the immune checkpoint inhibitor pembrolizumab associated to trastuzumab. Int J Cardiol. 2019;292:171-9.

7. Crosby $\mathrm{CM}$, Kronenberg M. Tissue-specific functions of invariant natural killer T cells. Nat Rev Immunol. 2018;18:559-74.

8. Salio M, Silk JD, Jones EY, Cerundolo V. Biology of CD1- and MR1-restricted T cells. Annu Rev Immunol. 2014;32:323-66.

9. Nagarajan NA, Kronenberg M. Invariant NKT cells amplify the innate immune response to lipopolysaccharide. J Immunol. 2007;178:2706-13.

10. Berzins SP, Smyth MJ, Baxter AG. Presumed guilty: natural killer T cell defects and human disease. Nat Rev Immunol. 2011;11:131-42.

11. Molling JW, Kolgen W, van der Vliet HJ, Boomsma MF, Kruizenga H, Smorenburg $\mathrm{CH}$, et al. Peripheral blood IFN-gamma-secreting Valpha24 ${ }^{+}$Vbeta $11^{+}$NKT cell numbers are decreased in cancer patients independent of tumor type or tumor load. Int J Cancer. 2005;116:87-93.

12. Molling JW, Langius JA, Langendijk JA, Leemans $C R$, Bontkes $H J$, van der Vliet $H J$, et al. Low levels of circulating invariant natural killer $\mathrm{T}$ cells predict poor clinical outcome in patients with head and neck squamous cell carcinoma. J Clin Oncol. 2007;25:862-8.

13. Motohashi S, Nagato K, Kunii N, Yamamoto H, Yamasaki K, Okita K, et al. A phase I-II study of alpha-galactosylceramide-pulsed IL-2/GM-CSF-cultured peripheral blood mononuclear cells in patients with advanced and recurrent non-small cell lung cancer. J Immunol. 2009;182:2492-501.

14. Chang DH, Osman K, Connolly J, Kukreja A, Krasovsky J, Pack M, et al. Sustained expansion of NKT cells and antigen-specific T cells after injection of alphagalactosyl-ceramide loaded mature dendritic cells in cancer patients. J Exp Med. 2005;201:1503-17.

15. Uchida T, Horiguchi S, Tanaka Y, Yamamoto H, Kunii N, Motohashi S, et al. Phase I study of alpha-galactosylceramide-pulsed antigen presenting cells administration to the nasal submucosa in unresectable or recurrent head and neck cancer. Cancer Immunol Immunother. 2008;57:337-45.

16. Ishikawa A, Motohashi S, Ishikawa E, Fuchida H, Higashino K, Otsuji M, et al. A phase I study of alpha-galactosylceramide (KRN7000)-pulsed dendritic cells in patients with advanced and recurrent non-small cell lung cancer. Clin Cancer Res. 2005;11:1910-7.
17. Nieda M, Okai M, Tazbirkova A, Lin H, Yamaura A, Ide $K$, et al. Therapeutic activation of Valpha24 ${ }^{+}$Vbeta $11^{+}$NKT cells in human subjects results in highly coordinated secondary activation of acquired and innate immunity. Blood 2004;103:383-9.

18. Giaccone G, Punt CJ, Ando Y, Ruijter R, Nishi N, Peters M, et al. A phase I study of the natural killer T-cell ligand alpha-galactosylceramide (KRN7000) in patients with solid tumors. Clin Cancer Res. 2002;8:3702-9.

19. Motohashi S, Ishikawa A, Ishikawa E, Otsuji M, lizasa T, Hanaoka $H$, et al. A phase I study of in vitro expanded natural killer T cells in patients with advanced and recurrent non-small cell lung cancer. Clin Cancer Res. 2006;12:6079-86.

20. Chuang HC, Sheu WH, Lin YT, Tsai CY, Yang CY, Cheng YJ, et al. HGK/MAP4K4 deficiency induces TRAF2 stabilization and Th17 differentiation leading to insulin resistance. Nat Commun. 2014;5:4602.

21. Xiao H, Li H, Wang JJ, Zhang JS, Shen J, An XB, et al. IL-18 cleavage triggers cardiac inflammation and fibrosis upon beta-adrenergic insult. Eur Heart $\mathrm{J}$. 2018;39:60-9.

22. Gladka MM, Molenaar $B$, de Ruiter $H$, van der Elst $S$, Tsui $H$, Versteeg $D$, et al. Single-cell sequencing of the healthy and diseased heart reveals cytoskeletonassociated protein 4 as a new modulator of fibroblasts activation. Circulation. 2018;138:166-80

23. Aronoff L, Epelman S, Clemente-Casares X. Isolation and identification of extravascular immune cells of the heart. J Vis Exp. 2018;23:58114.

24. Qu X, Liu Y, Cao D, Chen J, Liu Z, Ji H, et al. BMP10 preserves cardiac function through its dual-activation of SMAD-mediated and STAT3-mediated pathways. J Biol Chem. 2019;294:19877-88.

25. Zhang X, Goncalves R, Mosser DM. The isolation and characterization of murine macrophages. Curr Protoc Immunol. 2008; Chapter 14:Unit 14.1. https://doi.org/ 10.1002/0471142735.im1401s83.

26. Ando $T$, Ito $H$, Ohtaki H, Seishima M. Toll-like receptor agonists and alphagalactosylceramide synergistically enhance the production of interferon-gamma in murine splenocytes. Sci Rep. 2013;3:2559.

27. Bonaca MP, Olenchock BA, Salem JE, Wiviott SD, Ederhy S, Cohen A, et al Myocarditis in the setting of cancer therapeutics: proposed case definitions for emerging clinical syndromes in cardio-oncology. Circulation. 2019;140:80-91.

28. Mann DL. Innate immunity and the failing heart: the cytokine hypothesis revisited. Circ Res. 2015;116:1254-68.

29. Frangogiannis NG. The inflammatory response in myocardial injury, repair, and remodelling. Nat Rev Cardiol. 2014;11:255-65.

30. Frangogiannis NG. Cardiac fibrosis: cell biological mechanisms, molecular pathways and therapeutic opportunities. Mol Asp Med. 2019;65:70-99.

31. Savvatis K, Muller I, Frohlich M, Pappritz K, Zietsch C, Hamdani N, et al. Interleukin6 receptor inhibition modulates the immune reaction and restores titin phosphorylation in experimental myocarditis. Basic Res Cardiol. 2014;109:449.

32. Swirski FK, Nahrendorf M. Cardioimmunology: the immune system in cardiac homeostasis and disease. Nat Rev Immunol. 2018;18:733-44.

33. Pinto AR, llinykh A, Ivey MJ, Kuwabara JT, D'Antoni ML, Debuque R, et al. Revisiting cardiac cellular composition. Circ Res. 2016;118:400-9.

34. Bajpai G, Bredemeyer A, Li W, Zaitsev K, Koenig AL, Lokshina I, et al. Tissue resident $\mathrm{CCR}^{-}$and $\mathrm{CCR}^{+}$cardiac macrophages differentially orchestrate monocyte recruitment and fate specification following myocardial injury. Circ Res. 2019;124:263-78.

35. Dewald O, Zymek P, Winkelmann K, Koerting A, Ren G, Abou-Khamis T, et al. $\mathrm{CCL} 2 /$ monocyte chemoattractant protein-1 regulates inflammatory responses critical to healing myocardial infarcts. Circ Res. 2005;96:881-9.

36. Hulsmans M, Clauss S, Xiao L, Aguirre AD, King KR, Hanley A, et al. Macrophages facilitate electrical conduction in the heart. Cell. 2017;169:510-22.e20.

37. Van Linthout $S$, Miteva $K$, Tschope $C$. Crosstalk between fibroblasts and inflammatory cells. Cardiovasc Res. 2014;102:258-69.

38. Tan C, Tasaka H, Yu KP, Murphy ML, Karnofsky DA. Daunomycin, an antitumor antibiotic, in the treatment of neoplastic disease. Clinical evaluation with special reference to childhood leukemia. Cancer. 1967;20:333-53.

39. Xu X, Huang W, Heczey A, Liu D, Guo L, Wood M, et al. NKT cells coexpressing a GD2-specific chimeric antigen receptor and IL15 show enhanced in vivo persistence and antitumor activity against neuroblastoma. Clin Cancer Res. 2019;25:7126-38.

40. Johnson DB, Balko JM, Compton ML, Chalkias S, Gorham J, Xu Y, et al. Fulminant myocarditis with combination immune checkpoint blockade. N Engl J Med. 2016;375:1749-55.

41. Felker GM, Thompson RE, Hare JM, Hruban RH, Clemetson DE, Howard DL, et al. Underlying causes and long-term survival in patients with initially unexplained cardiomyopathy. N Engl J Med. 2000;342:1077-84.

42. Ganatra S, Carver JR, Hayek SS, Ky B, Leja MJ, Lenihan DJ, et al. Chimeric antigen receptor T-cell therapy for cancer and heart: JACC council perspectives. J Am Coll Cardiol. 2019;74:3153-63.

43. Ganatra S, Parikh R, Neilan TG. Cardiotoxicity of immune therapy. Cardiol Clin 2019;37:385-97. 
44. Neelapu SS, Tummala S, Kebriaei P, Wierda W, Gutierrez C, Locke FL, et al. Chimeric antigen receptor T-cell therapy-assessment and management of toxicities. Nat Rev Clin Oncol. 2018;15:47-62.

45. Miyaki E, Hiraga N, Imamura M, Uchida $T$, Kan $H$, Tsuge $M$, et al. Interferon alpha treatment stimulates interferon gamma expression in type I NKT cells and enhances their antiviral effect against hepatitis $C$ virus. PLoS One. 2017;12:e0172412.

46. Wolf MJ, Adili A, Piotrowitz K, Abdullah Z, Boege Y, Stemmer K, et al. Metabolic activation of intrahepatic $\mathrm{CD}^{+}{ }^{+} \mathrm{T}$ cells and NKT cells causes nonalcoholic steatohepatitis and liver cancer via cross-talk with hepatocytes. Cancer Cell. 2014;26:549-64.

47. Homma T, Kinugawa S, Takahashi M, Sobirin MA, Saito A, Fukushima A, et al. Activation of invariant natural killer $T$ cells by alpha-galactosylceramide ameliorates myocardial ischemia/reperfusion injury in mice. J Mol Cell Cardiol. 2013;62:179-88.

48. Wang HX, Li WJ, Hou CL, Lai S, Zhang YL, Tian C, et al. CD1d-dependent natural killer $\mathrm{T}$ cells attenuate angiotensin II-induced cardiac remodelling via IL-10 signalling in mice. Cardiovasc Res. 2019;115:83-93.

49. Benjamin IJ, Jalil JE, Tan LB, Cho K, Weber KT, Clark WA. Isoproterenol-induced myocardial fibrosis in relation to myocyte necrosis. Circ Res. 1989;65:657-70.

50. Zhang G, Zhang X, Li D, Tian J, Jiang W. Long-term oral atazanavir attenuates myocardial infarction-induced cardiac fibrosis. Eur J Pharmacol. 2018;828:97-102.

51. Sobirin MA, Kinugawa S, Takahashi M, Fukushima A, Homma T, Ono T, et al. Activation of natural killer T cells ameliorates postinfarct cardiac remodeling and failure in mice. Circ Res. 2012;111:1037-47. 